\title{
Report on the Educational Process for the Promotion of Health of Women Attended in a Reference Center of Social Assistance
}

\author{
Daiane Pontes Bezerra, Jéssica Raissa Carlos Gomes, Maria Izabel Ludovico de Souza, \\ Ana Hortência de Azevedo Medeiros, Daísy Vieira de Araújo, Fábia Barbosa de Andrade \\ Faculty of Health Sciences of Trairi (FACISA), Federal University of Rio Grande do Norte (UFRN), Santa Cruz, \\ Brazil \\ Email: dayane.pontesbezerra@gmail.com, jessica_rcg15@hotmail.com,mariaizabel0@gmail.com, \\ anna.hortencia@yahoo.com.br, mestredaisy@yahoo.com.br, fabiabarbosabr@yahoo.com.br
}

Received 11 May 2015; accepted 28 December 2015; published 31 December 2015

Copyright (C) 2015 by authors and Scientific Research Publishing Inc.

This work is licensed under the Creative Commons Attribution International License (CC BY). http://creativecommons.org/licenses/by/4.0/

C) (i) Open Access

\section{Abstract}

This article discusses one experienced by students and preceptors of Programs Pro-Pet-Health and Health of the Federal University of Rio Grande do Norte/Faculty of Health Sciences of Trairí in the Reference Center for Social Assistance (CRAS) in the municipality of experience Santa Cruz/RN, with a view to the relationship between preventive health activities and social assistance. The proposed work of Pro-Pet in the assistance unit sought to unravel the lifestyle of the target audience in order to know the risk factors and suggest the adoption of health measures for disease prevention. Work to guide the educational process for health promotion with socioeconomic and cultural contextualization built on scientific papers surveyed in Lilacs and Scielo data was used. On average, 12 women aged between 35 and 60 years participated in the group. Eight group sessions occurred in the period from March to May 2014. Regarding work methodologies, we used dynamic integration and self-knowledge; dialogued lectures; lectures; reports of experiences; thematic workshops; educational videos; wheels conversation complemented by the use of texts and poems; as well as application of the checklist in conducting health and anthropometry. The experience helped identify the characteristics of the group and plan understandable and meaningful guidance for women, facilitating the understanding of the importance of self-care in preventing disease.

\section{Keywords}

Health Promotion, Health Education, Women's Health 


\section{Introduction}

Currently, the scientific papers in the country show that the health of the woman is the target of reflection by a range of professionals. In this sense, people connected with various areas of expertise in working together, have directed the look on this universe in order to understand it and suggest possible interventions.

A tool to facilitate the formulation of gender policies, especially toward women, is to understand the types of work performed by them. Thus, their practical needs arise those identified through their socially accepted roles in society by condition mother, breadwinner, provider of home and professional. As Fonseca said [1], "those needs are a response to immediate perceived necessity, identified within a specific context and are related to inadequacies in living conditions such as water supply, the health care”, etc.

As for practices whose aim is the strengthening of links, we discuss the "dimension in which individuals extend control over their lives by participating in groups to the changes in the social and political reality in which they live" [1].

Health promotion consists of preventive actions dedicated to a public that is likely the determinants of disease, so the Reorientation National Program for Professional Training in Health (PRO-Health) and the Education Program for Working for Health (PET-Health), linked to the Federal University of Rio Grande do Norte/Faculty of Health Sciences Trairi, implemented the health education activities among the population of Santa Cruz, Rio Grande do Norte, Brazil, through the network Psychosocial and Network Stork, in order to provide knowledge for users of health and social care.

The health-disease process is related to a number of factors: social, cultural, economic and political, and above all the joint social care and health network development initiatives aimed at disease prevention and health promotion. With the program the Pro-health and Pet-health, the activities developed by fellows and nursing volunteers, Physiotherapy and Nutrition of the higher education institution, tutors (professional) and mentors (teachers) began in March 2014, a job in the Reference Center Social Assistance (CRAS) in the municipality of Santa Cruz/RN to the link between preventive health-related activities.

Taking consideration of the choice of the women in CRAS group, among others existing, there was the need to prove the self-care practice and disease prevention used by the target audience and the high rate of chronic diseases, including diabetes mellitus, hypertension and obesity.

The purpose of this article, therefore, is to report the experience lived by students, preceptors and tutors Pro-Pet-Health and Health with a group of women attending the said assistance unit.

\section{Methodology}

This is an exploratory and descriptive study, anchored in experience report experienced by students, preceptors and tutors Pro-Pet-Health and Health at CRAS Set neighborhood Canon Mount (CCM), the municipality of Santa Cruz/RN.

The proposed project work in the assistance unit sought to unravel the lifestyle of women attending the service in order to meet the health risk factors and suggest the adoption of measures for the prevention of diseases.

Work to guide the educational process for health promotion with socioeconomic and cultural contextualization built on scientific papers surveyed in Lilacs and SciELO data was used. For Brazil Camila Moreira et al. [2] "health education is one way of spreading the knowledge and activity of the participants are active agents in the learning and empowerment to share responsibility for self-care process".

Participated in the group, on average, 12 women aged between 35 and 60 years. Eight group sessions occurred in the period from March to May 2014 Regarding work methodologies, we used dynamic integration and self-knowledge; dialogued lectures; lectures; reports of experiences; thematic workshops; educational videos; wheels conversation complemented by the use of texts and poems; well as application of the checklist in conducting health and anthropometry.

\section{Results and Discussion}

\subsection{Single Social Assistance System and Unified Health System}

The Unified Social Assistance System (SUAS), created by the Ministry of Social Development and Fight against Hunger (MDS) by Federal Law No. 8742 in December 1993 and amended by Law No. 12435 of July 2011, consists of a system public non-contributory, decentralized and participatory used to operationalize the 
social assistance in Brazil. Their structural axes are "socio-family matricialidade; political and administrative decentralization; territorialization; financing; ensuring different levels of attention (basic and special) social protection; shared management and social control with popular participation” [3].

As well as health, public policy, social assistance is the citizen's right and duty of the State, being a participant in the non-contributory Social Security policy, as laid down in our constitution 1988 article 194 [4].

Social, basic and special protections are offered, respectively, by the Reference Center for Social Assistance (CRAS) and Center for Social Assistance Specialized Reference (CREAS). CRAS is called "the municipal unit, located in areas with higher rates of social vulnerability and risk, for the articulation of social assistance services and the provision of services, programs, projects and social assistance to families” [3].

For the sole Health System (SUS), it was established by the 1988 Federal Constitution in Article 196 and is regulated by Law. 8080/1990 [4] which operationalizes the public health service. Its creation was the result of a lasting social and complex process. For some, the institution has produced the desired effect; for still others, there is a long way to go. There are those who consider the creation of the SUS as the end of separation between individuals included and which were not included economically.

Under this study, it can be stated that the policies of Social Welfare and health in an integrated way, has an important role in women's health, considered from episodes of suffering characterized by routine disease process, as well as by stress constant.

\subsection{The Importance of Self-Care in Disease Prevention}

Historically humans differ from other terrestrial beings due to its teleological capacity. From this perspective, Bub et al. [5] suggest that only the first feature "ability to reflect on yourself and your environment, symbolize that experience and use symbolic creations in thought".

In this sense, the process of teaching-learning arises as an opportunity for knowledge to humans because of their reflective capacity.

Regarding the context of health education, it is argued that the pursuit of knowledge construction by the individual to a possible behavioral change enables them to recognize the importance of preventing disease and injury, which is directly related to health promotion and the concept of self-care.

Respect to decision making by an individual for the prevention and treatment of their disease are various definitions of the self-care, as Derntl and Watanabe [6] says. And reiterate stating that refers to individual attitudes related to health improvement. Orem cited Torres, Davim and Nobrega [7], the practice of self-care relates to "activities that a person starts and performs on its own will to keep your life, health and wellness".

It is noteworthy also that the self-care actions include spontaneous and intentional aspects, which are linked particularly to the desire to care for yourself. Factors such as age, gender, health status, sociocultural orientation, health care system, methods of diagnosis and treatment, as well as family members, directly influence the initiative to self-care [5].

Considering the self-care as a health promotion strategy, which relates exclusively to adoption of practices and knowledge which induce favorable attitudes to physical and mental well-being, the group of students, preceptors and tutors Pro-Pet-Health and Health recognized in women users of the services of CRAS learning ability about the health-disease process, as well as the opportunity to become multipliers of the knowledge acquired in the community in which they reside.

Thus, the proposed project work in the assistance unit sought to unravel the lifestyle of the target audience in order to meet the health risk factors and suggest the adoption of measures for the prevention of diseases, such as avoiding harmful habits, stimulate healthy eating and physical exercise.

\subsection{Socio Work of Pro-Health and Pet-Health}

In 2005, the National Programme of Reorientation of Vocational Training in Health was established by the Interministerial MS/MEC No. 2101 aimed at reorienting vocational training through the integration of teaching and learning and encouraging the provision of services to the community, according to reports in the Ministry of Health in its publications [8]. Courses in Nursing, Medicine and Dentistry pioneered this initiative. Just two years later, the other undergraduate courses related to health were covered by the program [8].

The importance of the Pro-Health in the graduate training process occurs, according to Valente et al. [9] due to the change of perspective that he considered "the individual assistance focused on specialties, for a process 
that takes into account the social, historical, economic and cultural population”. Thus, it was possible to build new parameters for training, whose main objective is the integration of courses in the area of health.

The implementation strategy of the Pro-Health, according to Valente et al. [9]:

Consisted of articulation between higher education institutions and the public servant Health and potentiated responses to the specific needs of the population, through the formation of human resources, knowledge production and the provision of services in order to strengthen the SUS.

As the processes of reorientation training on Pro-Health, there are three axes transformation: 1) Theoretical Orientation; 2) Scenarios and Practice; 3) Educational Guidance. In the first, priority is given to: the determinants of health as well as social illness; the assessment of the Primary Care process from clinical research; guidance on practices and; continuing education of professionals. Then, show the processes of active learning; clinical practice with analytical sense; the association between theory and practice; the search for the solution of problems through learning and; formative and summative evaluation. Finally, the third axis, whose premise is based: the inclusion of various environments and levels of care; the importance of reference and counter-reference; the wide coverage of pathology and; mainly on interaction with the community, students and the multidisciplinary teams [9].

Regarding the Education Program at Work Health, established by Interministerial MS/MEC no. 1802/08, Caldas et al. [10] claim that it is an initiative of the Ministries of Health and Education which is meant to "create learning groups in strategic areas for the public health service areas of greatest need or be able to meet a greater number of people in a community”. Moreover, the program encourages the articulation of the teaching-researchextension, providing college students the operation of the equipment in the activities Health System that offer primary care to the population. With this program, therefore, the Ministry of Health seeks to stimulate the formation of professionals with technical and scientific quality, thereby providing proper knowledge about the needs of their community and region.

To Neves et al. [11]:

The establishment of the university extension stems from the need to integrate the Higher Education Community. Given this, the Extension plays mediator between these two universes role, diffusing knowledge and technology, expanding worldviews, intervening, promoting social and human rights practices, assisting in the development of a critical and academic communities own and met political consciousness.

The Pet-Health consists of tutors, mentors and monitors. The first are the teachers of Higher Education Institutions (HEIs) that guide and encourage the production of knowledge gained through the experiences provided by the program; Professionals linked to health care services are called preceptors and have the function of guiding students in services; For the latter, students duly enrolled in HEIs, receive guidance from tutors and mentors and develop activities in the social assistance network drives, as well as produce and publish academic papers at scientific meetings.

Neves et al. [11], highlight the importance of this program is given to academics, especially through the humanization process by which experience, given that they are led to understand the problems of the community in which they live, meeting patients in a holistic approach, and learn to work where conditions and tools are not always ideal, enhancing their creativity.

In the case of work performed by staff at CRAS/CCM, as it is popularly known, there is the educational process for health promotion of women attending the unit. CRAS is called the municipal unit, located in areas with higher rates of social vulnerability and risk, for the articulation of social assistance services and the provision of services, programs and social assistance to families [12] projects.

Initially there was a meeting with the technical service team to define the actions to be undertaken by students and tutors together with the users. Among the points covered, cites the importance of interdisciplinarity for development work; co-responsibility between agencies; confidentiality and professional ethics; the methodologies of the psychosocial work area; well as the need for planning activities.

In a second step, was discussed issues of interest to women for possible interventions and presentation about the work done by the Psychosocial Network Pro-Pet-Health and Health. Topics such as healthy eating, hypertension, diabetes mellitus, breast cancer and cervical cancers, relaxation techniques, gender violence were mentioned by users as the most desirable for interventions.

Under this prism, eight group sessions were conducted between March and May 2014 with women treated at 
CRAS/CCM, aiming to inform them about disease prevention from a social-educational bias. It can be said that the first meeting had the role to enlighten them as to the performance of the Pro-Pet and its importance to the community. Moreover, provided the strengthening of ties between the actors involved in the project.

Regarding working methodologies, we used dynamic integration and self-knowledge; dialogued lectures; lectures; reports of experiences; thematic workshops; educational videos; wheels conversation complemented by the use of texts and poems; well as application of the checklist in conducting health and anthropometry. It should be noted that each group session was designed for all students of Pro-Pet that were running activities with the CRAS and developed according to their area of training, namely: Nutrition, Nursing and Physical Therapy.

It was noticeable that the methodologies used valued the construction of teaching and learning, in that it provided the active participation of students, as well as the users that, in fact, showed a questioning stance, based on their daily lives. Furthermore, combined with experience linking theory and practice, knowledge and work, education and life. Within this perspective, too, we learn a lot of new knowledge, given the direct contact with the health demands linked expressions of vulnerabilities and social risks such as violence, malnutrition, family breakdown, among others.

\subsection{The Importance of Application Management Tools for the Organization of Work Processes}

The application of analytical tools in defining the target audience, as well as the course of serving this along to services, programs and projects enables professionals needed about the user profile and especially the goals and intervention strategies to be adopted knowledge to overcome challenges posed to daily work.

For Franco [13], "in relation to Technical healthcare health models, we have insisted on the thesis that they assume certain configuration, according to the processes and technologies used in the production work of health care". Considering this statement, it appears that a tool that enables the user understanding their needs and reflects the excellence of the work being performed.

Usually is conventionally assess, among multidisciplinary teams, the service provided by the community welfare institutions through discussions on the structural aspects, triggering therefore the production of a management report. This fact does not always prove effective, given that it is necessary to understand the full service to users and this includes knowledge of your profile and the demands for intervention.

That said, as Franco [13], to succeed on a situational assessment of a health care institution, you must "find the general context, its place the service in question; identify the network of relationships inter and intra equipment analyzed and clarify the commitments among actors in the operational and decision-making arena".

As the tool used by the Pro-Pet staff in situational assessment of CRAS mentioned, it cites the "flowchart descriptor" conceptualized by Merhy and Chakkour et al. [14] as a graphical representation of the work process, seeking to realize the paths taken user when searching assistance and their inclusion in the service.

The construction of the flowchart CRAS took collectively, seeking users in the registration forms, as well as in national classification of socio-assistance services [12], the steps taken by the user in search of the resolution of your problem.

Specifically, this instrument was very efficient, since it enabled the identification of the daily work of the CRAS and, especially, the path taken by the user within the unit, either through spontaneous demand and/or active search. Also revealed in the critical nodes that pervade the daily lives of the crew, since the individual visits to the referrals made to social assistance network.

This whole range of knowledge acquired through the application of workflow descriptor provided a satisfactory intervention among women living group of equipment. Furthermore, it was realized a number of existing and potential users in the territory of CRAS, which in turn will guide the work of technical staff in the future.

The graphical representation of the services offered in the CRAS is as follows: [Figure 1].

\section{Conclusions}

From the realization of actions of health education for women attending a health care unit, as a strategy for disease prevention and control of diseases, the students linked to Pro-Pet-Health and Health could reflect on the importance of articulating the theory and professional practice, as well as recognize the valuable role of interdisciplinary and multidisciplinary team in the execution of a job. In addition, they managed to share their scien- 


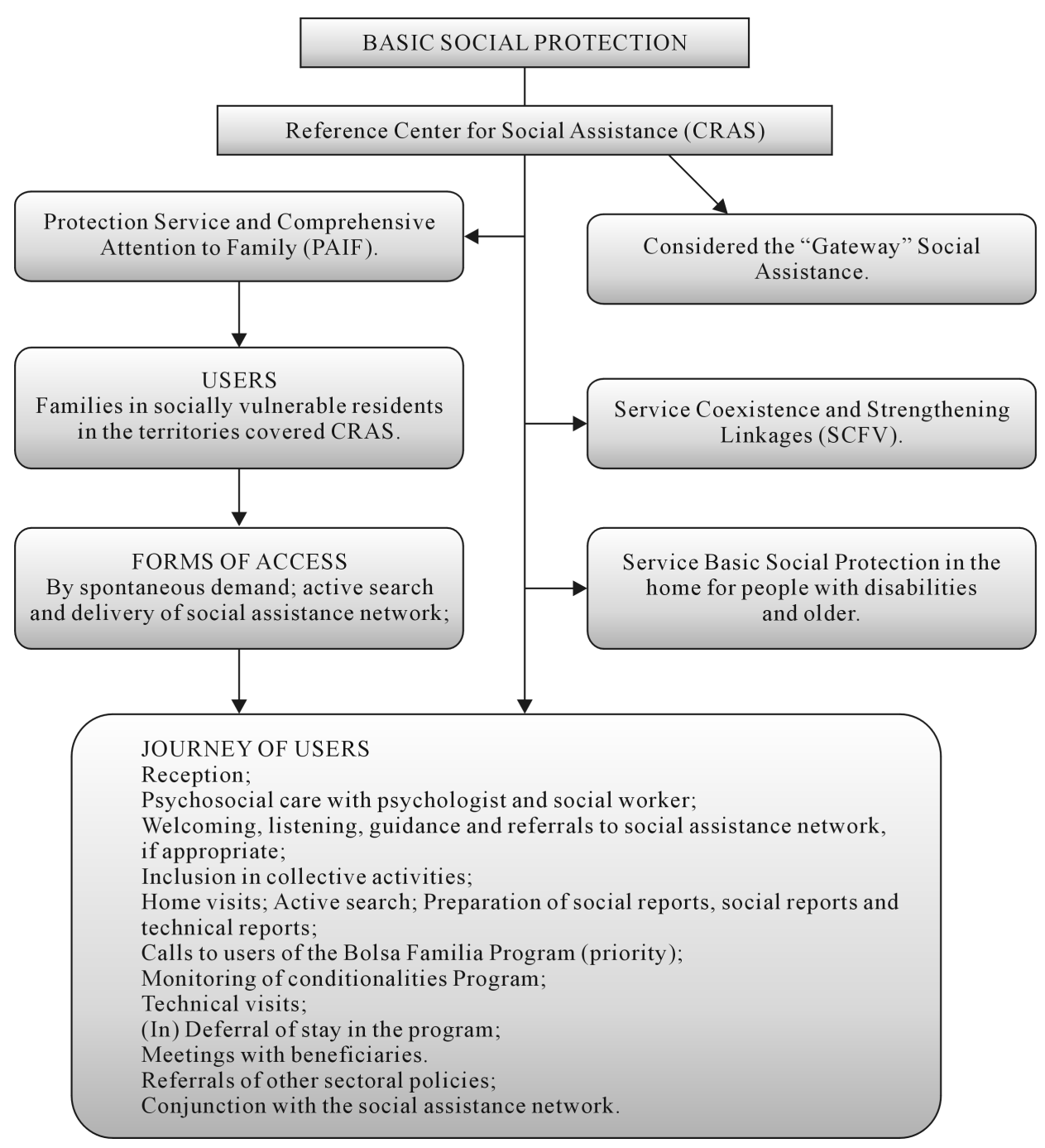

Figure 1. Representation of the services offered in the CRAS.

tific knowledge and their empirical experiences which, therefore, enabled the audience to discover their potential and their empowerment.

Regarding the challenges posed to daily work, students and preceptors, along with academic tutors, are able to overcome them day after day, finding viable alternatives to run a quality service.

It was noted also the importance of this work across the technical staff of the service as it existed on the drive demand for professionals linked to the health sector to work with issues related to its jurisdiction. This corroborates the hypothesis that, currently, there are new demands placed on the professional who, in turn, should have a critical, committed and ethical attitude in order to achieve this new level of knowledge.

\section{References}

[1] Fonseca, R.M.G.S. (1998) Woman, Rights and Health: Rethinking the Cohesive Connection. Transinf [Internet], 3-32.

[2] Moreira, C.B., Fernandes, A.F.C., Gomes, M.F.A., et al. (2013) Article Report of Educational Strategy Experience Lived with Mastectomy Women: Report of Educational Experience. Journal of Nursing UFPE Online, 7, 5-8.

[3] Brazil (2011) Law 12.435 of July 2011.

[4] Brazil Constitution (1988) Constitution of the Federative Republic of Brazil. Federal Senate, Brasília, DF.

[5] Bub, M.B.C., Medrano, C., Smith, C.D., Wink, S., Liss, P.E. and Santos, E.K.A. (2007) The Notion of Care of Yourself and the Concept of Self-Care in Nursing. Text \& Context Nursing Journal, 15, 152-157. 
http://dx.doi.org/10.1590/S0104-07072006000500018

[6] Derntl, A.M. and Watanabe, H.A.W. (2004) Health Promotion. In: Litvoc, J. And Brito, F.C., Organizadores, Aging: Prevention and Health Promotion, Atheneu, São Paulo (SP).

[7] Torres, R.B.C., Davim, R.M.B. and Nobrega, M.M.L. (1999) Application of the Nursing Process Based on the Theory Pray: Literature Review. Revista Latino-Americana de Enfermagem, 7, 47-53.

[8] Brazil Ministry of Health (2007) Ministry of Education. Reorientation National Program for Professional Training in Health. Publisher of the Health Ministry, Brasilia.

[9] Valente, S.G.S.C., Gomes, H.F. and Alves, F.B. (2010) Pro-Health: A New Educational Experience in Vocational Training. Práxis Educacional, 6, 227-237.

[10] Caldas, J.B., Lopes, A.C.S., Mendonça, R.D., et al. (2012) Students' Views of the Educational Program for Health Work. Revista Brasileira de Educação Médica, 36, 33-41.

[11] Neves, T.V., Valentine, I.M., Souza, E.B., et al. (2012) Experience of Academic PET-Health/Health Surveillance. Revista Eletrônica Gestão \& Saúde, 3, 1198-210.

[12] Brazil (2009) National Classification of Social Assistance Services. 1-43.

[13] Franco, T.B. (2003) The Flowchart Use Descriptor and Therapeutic Projects for Health Services Analysis in Support of Planning: The Case of Light-MG. 1-30.

http://www.professores.uff.br/tuliofranco/textos/fluxograma_descritor_e_projetos_terapeuticos_caso_de_luz_tulio_fra nco.pdf

[14] Merhy, E.E. and Onocko, R. (1997) Health Act: A Challenge for the Public. Editora Hucitec, São Paulo, 1-78. 